\title{
Identification and characterization of Prunus persica miRNAs in response to UVB radiation in greenhouse through high- throughput sequencing
}

Shaoxuan $\mathrm{Li}^{1,2}$, Zhanru Shao ${ }^{3,4}$, Xiling $\mathrm{Fu}^{1,2}$, Wei Xiao ${ }^{1,2}$, Ling $\mathrm{Li}^{1,2}$, Ming Chen ${ }^{1,2}$, Mingyue Sun ${ }^{1,2}$, Dongmei $\mathrm{Li}^{1,2^{*}}$ and Dongsheng GaO $\mathrm{O}^{1,2^{*}}$

\begin{abstract}
Background: MicroRNAs (miRNAs) are small non-coding RNAs that regulate gene expression of target mRNAs involved in plant growth, development, and abiotic stress. As one of the most important model plants, peach (Prunus persica) has high agricultural significance and nutritional values. It is well adapted to be cultivated in greenhouse in which some auxiliary conditions like temperature, humidity, and UVB etc. are needed to ensure the fruit quality. However, little is known about the genomic information of $P$. persica under UVB supplement. Transcriptome and expression profiling data for this species are therefore important resources to better understand the biological mechanism of seed development, formation and plant adaptation to environmental change. Using a high-throughput miRNA sequencing, followed by qRT-PCR tests and physiological properties determination, we identified the responsive-miRNAs under low-dose UVB treatment and described the expression pattern and putative function of related miRNAs and target genes in chlorophyll and carbohydrate metabolism.
\end{abstract}

Results: A total of 164 known peach miRNAs belonging to 59 miRNA families and 109 putative novel miRNAs were identified. Some of these miRNAs were highly conserved in at least four other plant species. In total, 1794 and 1983 target genes for known and novel miRNAs were predicted, respectively. The differential expression profiles of miRNAs between the control and UVB-supplement group showed that UVB-responsive miRNAs were mainly involved in carbohydrate metabolism and signal transduction. UVB supplement stimulated peach to synthesize more chlorophyll and sugars, which was verified by qRT-PCR tests of related target genes and metabolites' content measurement.

Conclusion: The high-throughput sequencing data provided the most comprehensive miRNAs resource available for peach study. Our results identified a series of differentially expressed miRNAs/target genes that were predicted to be low-dose UVB-responsive. The correlation between transcriptional profiles and metabolites contents in UVB supplement groups gave novel clues for the regulatory mechanism of miRNAs in Prunus. Low-dose UVB supplement could increase the chlorophyll and sugar (sorbitol) contents via miRNA-target genes and therefore improve the fruit quality in protected cultivation of peaches.

Keywords: Prunus persica, UVB, MicroRNA, High-throughput sequencing, Chlorophyll and carbohydrates

\footnotetext{
*Correspondence: dmli2002@163.com; dsgao@sdau.edu.cn

${ }^{1}$ College of Horticulture Science and Engineering, Shandong Agricultural

University, Tai'an 271018, People's Republic of China

Full list of author information is available at the end of the article
} 


\section{Background}

As an important environment signal, sunlight provides energy for the growth and development of plants [1], but its ultraviolet (UV) radiation part causes abiotic stress potentially influence the biological processes of plants. Since the late 1980s when awareness of stratospheric ozone layer depletion triggered concerns about the potentially harmful effects of increased UVB radiation, many studies have shown that UVB causes non-specific damage to DNA, proteins and lipids [2-4]. On the other hand, there is overwhelming evidence that other than substantially impeding plant growth, lowdose UVB is an environmental regulator affecting gene expression, cellular and metabolic activities, and growth and development [5-8]. Whether UVB radiation is a stressor or a regulator is determined by the fluence rate and exposure time [4]. Nevertheless, the regulatory mechanism of plants responding to the UVB-lack environment, for example in the greenhouse where the UVB radiation level is $30 \%-70 \%$ lower than outdoors, were rarely reported [9].

Most of the photomorphogenic responses to low-dose UVB are mediated by the photoreceptor UV RESISTANCE LOCUS8 (UVR8). Subsequent structural and functional characterization revealed that the UVR8 has a unique regulatory mechanism in photoreception [10-12]. After UVB treatment, UVR8 interacts with the E3 ubiquitin ligase (transducin/WD40 repeat-like superfamily protein) CONSTITUTIVELY PHOTOMORPHOGENIC1 (COP1), following the ubiquitination of the basic leucinezipper (bZIP family) transcription factor ELONGATED HYPOCOTYL5 (HY5) which is primarily in the initiation of photo-morphogenesis [13-16].

MiRNAs, small endogenous non-coding RNAs approximately 21-24 nucleotides (nt) in length, play an important role in regulating gene expression at the post-transcriptional level [17-19]. A large number of miRNAs have been recently identified in plants via highthroughput sequencing, and numerous miRNAs have been entered into the miRBase 21. MiRNAs are involved in regulating growth, development, root initiation and development, hormone balance, floral morphogenesis and reproductive performance [20,21]. Stress-regulated miRNAs in plants confer resistance to the extreme conditions, including UVB, drought, salt, cold and heat. In addition, the expression of miRNAs can alter the behavior of plants in response to both abiotic and biotic stresses [21, 22]. Previous reports have shown that miRNA induction was involved in regulating auxin signaling via miR160, miR167 and miR393 thus, becoming an important strategy for photomorphism in plants [23].

China is the largest producer of both outside-grown and inside-grown peaches and nectarines in the world. There are nearly 16,000 ha of protected peach and nectarines cultivation, $2.3 \%$ of the total area [24]. As a new agricultural form, protected production has been rapidly developed. Peach (Prunus persica), which has been cultivated for more than 4000 years, is one of the most important fruits in the world [25]. Peach has a small genome and it reaches reproductive maturity in a relatively short time. In 2010, the Genome Sequencing Project of the peach double haploid cultivar 'Lovell' was completed, which generated, $230 \mathrm{Mb}$ genome sequence and 202 assembly scaffolds [26]. Therefore, peach is considered to be a useful forest model species for genetic and ecological research. Following these findings, several reports on the identification of miRNAs in different peach tissues have been published [27-29]. Meanwhile, peach has some unique biological features not commonly found in other model organisms, such as a 35 year juvenile period before blossom, the formation of fleshy fruit with a hardened endocarp and chillingrequirement dormancy mechanism [30-34]. Nectarine, because of its low-chill and nutritional value, is selected as one of the most important fruits in the protected cultivation industry which targeted early and high markets. In previous research, we found that the supplement of UVB radiation can improve the fruit quality and the ability to compete for $\mathrm{C}$-assimilate [35, 36]. Considering the distinct environment especially the light condition in greenhouse, more deep studies related to the molecular and metabolic mechanism under UVB irradiance are needed.

In this study, we generated over 2 billion bases of high-quality RNA sequence with Illumina platform. In a single run, we identified 31,763,592 raw sequences including thousands of seed target and metabolism genes. Our results identified a series of differentially expressed miRNAs/target genes that were predicted to be low-dose UVB-responsive. The correlation between transcriptional profiles and metabolites' contents helped elucidate the regulatory mechanisms of peach under the UVB supplement. Our findings of correlation among miRNA, target genes and metabolites provided clues for breeding with high-quality fruit and other properties which are suitable for greenhouse cultivation.

\section{Results}

\section{Analysis of miRNA sequences}

Using Illumina sequencing, a total of $74,119,581$ and $76,123,247$ raw reads were obtained from control and UVB-treatment groups, respectively (Table 1 ). After discarding 3' adapter deletions, insertion deletions, 5' adapter contaminants, poly- $\mathrm{A}$ sequences and sequences less than $18 \mathrm{nt}$ from the high-quality reads, 52,375,087 and $56,244,851$ clean reads were used for further analysis. The proportions of clean reads were $70.79 \%$ and 
Table 1 The quality control of the clean data

\begin{tabular}{llllllllll}
\hline Sample & Num. of Reads & Raw Clean Reads $\%$ & Remove Adapter\% & Insert Null \% & N \% & Too short \% & Poly-A \% & Too long \% & Low quality $\%$ \\
\hline CK1 & $23,619,871$ & $76.50 \%$ & $0.06 \%$ & $2.18 \%$ & $0.17 \%$ & $13.86 \%$ & $0.06 \%$ & $7.04 \%$ & $0.12 \%$ \\
CK2 & $25,100,163$ & $68.65 \%$ & $0.09 \%$ & $1.27 \%$ & $0.16 \%$ & $24.63 \%$ & $0.05 \%$ & $5.05 \%$ & $0.11 \%$ \\
CK3 & $25,399,547$ & $67.22 \%$ & $0.09 \%$ & $1.34 \%$ & $0.16 \%$ & $29.78 \%$ & $0.04 \%$ & $1.25 \%$ & $0.11 \%$ \\
T1 & $25,154,335$ & $74.96 \%$ & $0.07 \%$ & $2.16 \%$ & $0.17 \%$ & $15.86 \%$ & $0.06 \%$ & $6.60 \%$ & $0.11 \%$ \\
T2 & $26,168,148$ & $75.67 \%$ & $0.10 \%$ & $0.65 \%$ & $0.18 \%$ & $14.36 \%$ & $0.05 \%$ & $8.88 \%$ & $0.11 \%$ \\
T3 & $24,800,764$ & $70.92 \%$ & $0.11 \%$ & $0.64 \%$ & $0.16 \%$ & $21.37 \%$ & $0.05 \%$ & $6.65 \%$ & $0.11 \%$ \\
\hline
\end{tabular}

CK control groups without UVB treatment, $T$ UVB treatment groups

$\mathrm{N} \%$ means the percentage of loci that fail to distinguish specific bases

$73.85 \%$ of the total reads obtained from the two libraries, respectively.

The small RNA (sRNA) reads were typically 18 to $30 \mathrm{nt}$ in length (Fig. 1). Among these sequences, $21 \mathrm{nt}$ sRNAs were the most abundant in the two libraries, accounting for $16.56 \%$ and $13.22 \%$ of the total reads, followed by 24 nt sRNAs, which accounted for $11.79 \%$ and $10.26 \%$ of the total reads, respectively. Furthermore, we observed that the number of less than $24 \mathrm{nt}$ length sequences in the control libraries was more abundant than that in the treatment libraries $(74.08 \%$ and $64.14 \%$, respectively). Additionally, a large proportion of unique sequences ( $>85 \%$ in both libraries) were unclassified sRNAs, suggesting a broad existence of miRNAs in peach.

\section{Known miRNAs in peach}

Known miRNAs in peach affected by UVB were identified through homologous alignment analysis using the plant miRNA in miRBase 21. A total of 164 known miRNAs belonging to 59 families were obtained from the deep sequencing. The dominant miRNA families are shown in Additional file 1: Table S1, and most of these miRNAs were largely conserved in various plant species. The expression levels of a few miRNA families, such as miR166, miR1511 and miR398, were evidentially high in both libraries. Some conserved miRNAs were reported only in few species, such as miR3627 in five (Vitis vinifera, Populus trichocarpa, Malus domestica, Solanum tuberosum, and $P$. persica), miR1511 in three (M. domestica, S. tuberosum, and P. persica), while miR8133 only in P. persica.

MiRNAs have a broad range of expression levels, varying from several to millions of reads. Most of the conserved miRNAs were identified from the two libraries, and certain miRNAs were abundant in some samples but scarce or even lacking in other samples. For example, the expression of miR159 generated 323,238 and 128,812 reads in the CK and UVB libraries respectively. Moreover, the number of reads for different members of the same family varied widely. For example, the expression of miR7122a in both libraries generated 21,291 reads while only 417 reads of miR7122b in both libraries.

\section{Novel miRNAs in peach}

In the present study, 109 novel miRNAs from peach deep sequencing were identified (Additional file 2: Table S2). The most abundant miRNA was Pp04_27840-3p, with 33,630 and 42,292 reads in the UVB libraries and CK libraries, respectively. Many novel miRNAs from our database were conserved with miRNAs from other species to a certain degree $(<50 \%)$, such as Pp02_15663$5 \mathrm{p}$ and $\mathrm{Pp} 03-22,312-3 \mathrm{p}$ corresponding to miR172d and miR2950-5p in grape (Vitis vinifera), respectively.

\section{Differential expression of miRNA}

The comparison of the miRNA expression levels in CK and UVB groups showed that 164 known and 109 novel miRNAs were identified in the two libraries. The analysis of the differential expression of miRNAs in the UVB treatment and control libraries showed that 9 known and 6 novel differentially expressed miRNAs from the two libraries might play important roles in the UVB response(Fig. 2). In brief, 8 miRNAs were up-regulated, including Pp03-22,312-3p, Pp03-22,312-5p, Pp0519,842-3p, Pp06-35,148-3p, Pp06-35,148-5p, miR397, miRNA171d-3p and miRNA3627-5p, and 7 miRNAs were down-regulated, including miRNA395d, miRNA395e, miRNA7122b-5p, miRNA399a, miRNA399b, miRNA8133-3p, and Pp05-28,899-3p in UVB treatment.

\section{Target prediction and functional analysis}

A large number of targets were predicted for most differentially expressed miRNAs. As for the known miRNAs, there were 1928 pathways that accounted for the largest percentage of the total targets. The results of Gene ontology classification and top 30 preferential KEGG pathway analysis revealed that target genes of these miRNAs were involved in various biological and biochemical processes in plant growth and development (Figs. 3 and 4) (Additional file 3: Table S3, Additional file 4: Table S4), such as porphyrin and chlorophyll metabolism (pper00860), pentose and glucuronate interconversions (pper00040), citrate cycle (TCA cycle, pper04712 and pper00020), circadian rhythm - plant and metabolic pathways (pper01100). 


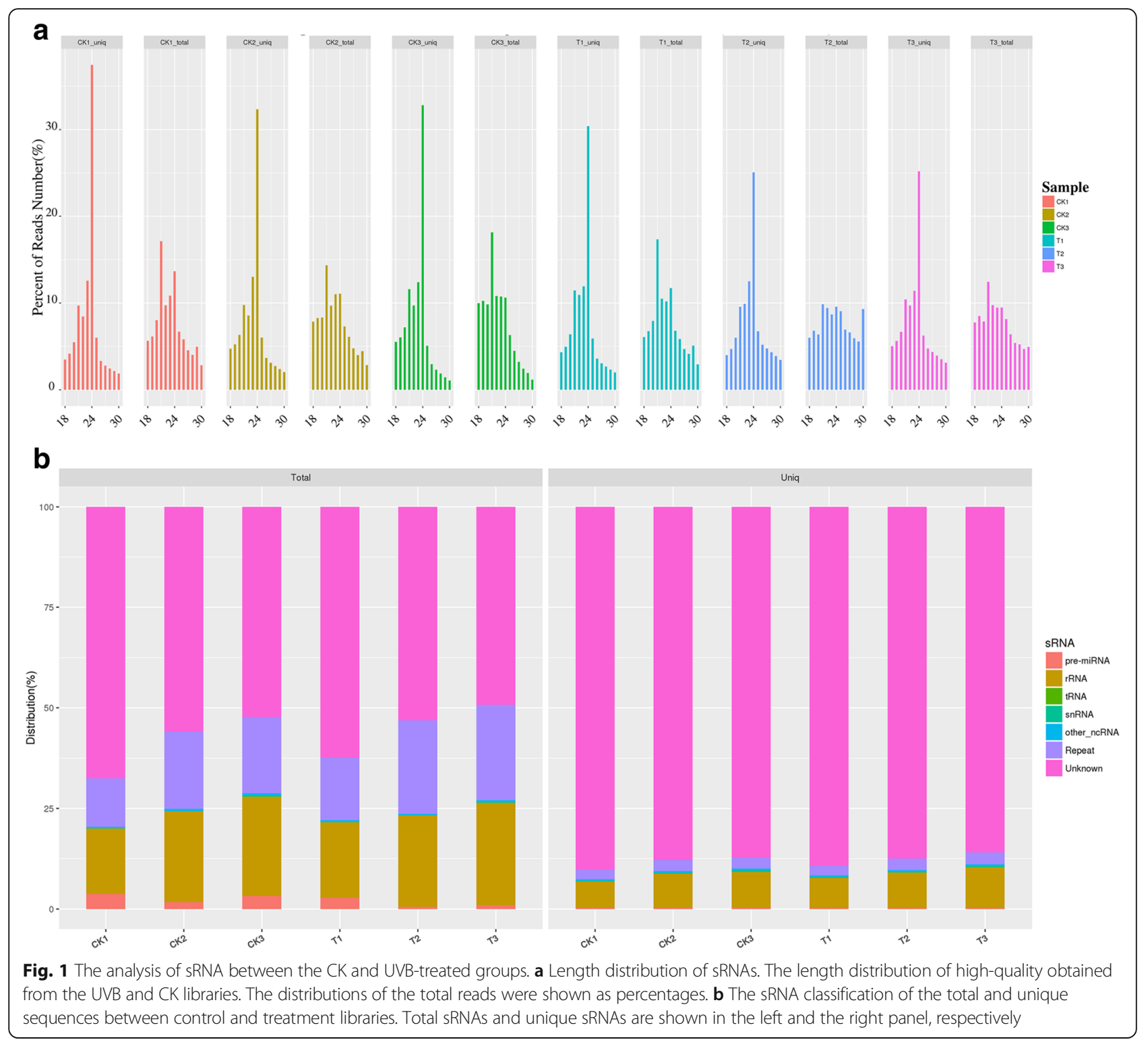

\section{Expression validation of UVB-responsive miRNA}

Totally, we verified the expression of 31 miRNAs (Table 2) via $\mathrm{qRT}$-PCR in which 15 miRNAs were retrieved in the database (Fig. 5). We selected miR5059 as reference miRNA [37] and 15 other miRNAs that related to UVB irradiance. The primers were listed in Additional file 5: Table S5. The qRT-PCR results showed the consistency with sequencing data except that miR397 levels under UVB treatment did not have significant difference with CK. The results showed some difference with the database. Many miRNAs were up-regulated other than downregulation from high-throughput sequencing, such as miR398a-5p (6.67-fold), miR398a-3p (2.09-fold), miR6263 (5.21-fold), miR6260 (2.31-fold), and miR319a (1.75-fold). On the contrary, miR1511 (2.31-fold), miR171c (2.31fold), and miR3627-3p (1.61-fold) were down-regulated under UVB treatment (Table 2; Fig. 5). Some conserved UVB-responsive miRNAs were not remarkably expressed such as miR156a, miR160a, miR166a, miR393a, miR402a which were considered to be involved in plant acclimation and adaptation of biotic or abiotic stress.

\section{Chlorophyll metabolism under UVB treatment}

KEGG pathway analysis of miRNA target genes (Fig. 4) showed that genes involved in chlorophyll metabolism might be significantly regulated by UVB. We determined chlorophyll content and crucial miRNA/genes expression levels to give clues for UVB effects on chlorophyll metabolism. Spectrophotometry results showed that the content of chlorophyll was gradually increased during the whole development period (Fig. 6a). Its content reached up to $5.24 \mathrm{mg} / \mathrm{g} \mathrm{Fw}$ in the mature stage of 

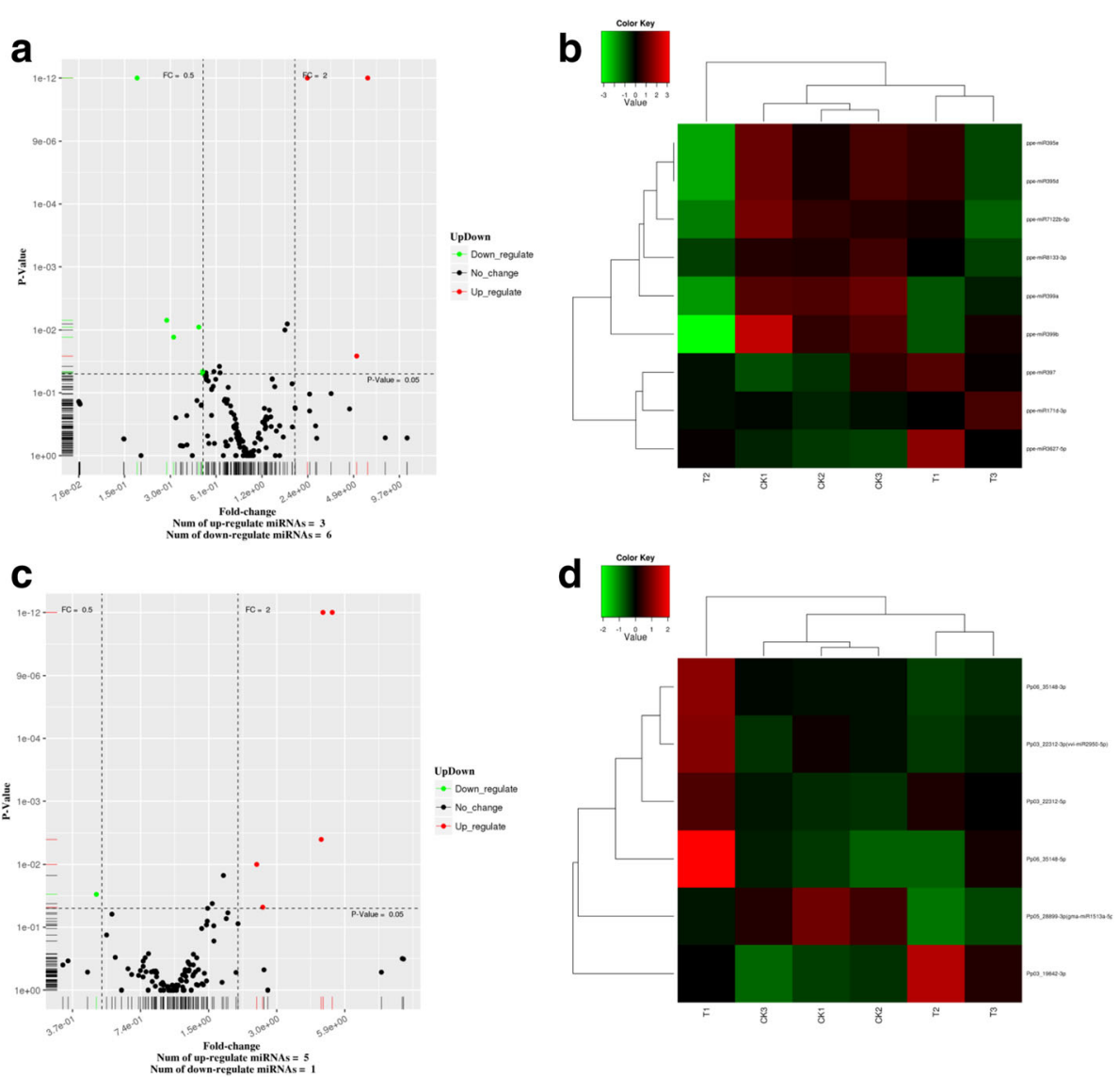

Fig. 2 The differentially expressed miRNAs between the CK and UVB-treated groups. a Scatter diagram of the differential read counts of known miRNAs. Each point in the figure represents a miRNA. b Heat map of differentially expressed known miRNAs between the control and UVB-treated groups. $\mathbf{c}$ Scatter diagram of the differential read counts of novel miRNAs. Each point in the figure represents a miRNA. $\mathbf{d}$ Heat map of differentially expressed novel miRNAs between the control and UVB-treated groups. Red points represent miRNAs showing a $>2$-fold change of expression; green points represent miRNAs showing $1 / 2<$ fold change $\leq 2$; black points represent miRNAs showing a fold change $\leq 1 / 2$

UVB-group, higher than $4.17 \mathrm{mg} / \mathrm{g} \mathrm{Fw}$ of the control group. The expression levels of miR171c in UVB-group were lower than the untreated samples, which was 2.3fold difference in the mature stage (Fig. 6b). Fig. 6c showed the different expression profiles of genes involved in chlorophyll metabolism. Scarecrow-like protein $(S C L)$, the target gene of miR171c, was highly up-regulated during the developmental period. On the contrary, pchlide oxidoreductase C (PORC), the downstream gene of $S C L$ was remarkably down-regulated. The others did not show significant difference between CK and UVB groups. Specifically, $S C L$ was up-regulated by 2.2 -fold after UVB treatment in fruit mature phase. PORC was down-regulated by 2.8 -fold (Fig. 6c). The gene information and sequences of primers were listed in Additional file 6: Table S6.

\section{Carbohydrate metabolism under UVB treatment}

Carbohydrate metabolism was another pathway targeted by miRNAs predicted by KEGG analysis. The contents of carbohydrates in leaves were significantly affected by UVB treatment (Fig. 7). Sorbitol, the main form of sugar, was up-regulated by 1.24-fold with UVB stimulation in the mature period (Fig. 7a), while the content of sucrose was dramatically decreased and did not show significant difference with/without UVB treatment (Fig. 7b). Fructose and glucose contents were increased with the developmental process, and the UVB-groups were higher than the control samples (Fig. 7c and d).

We screened 19 genes related with sugar metabolism from $P$. persica genome, and applied qRT-PCR assay to investigate the correlation between sugar synthesis and miRNA under UVB treatment (Fig. 8). The crucial genes involved in sucrose pathway did not show significant difference between UVB and control groups (Fig. 8a). However, genes in sorbitol metabolism were expressed distinctly after UVB stimulation (Fig. 8b). The expression levels of Sorbitol -3-orbitol -6-phosphate dehydrogenase $(S 6 P D H)$, NADP dependent sorbitol dehydrogenase $(N A D P-S D H)$ and Sorbitol transporter (SOT) were 


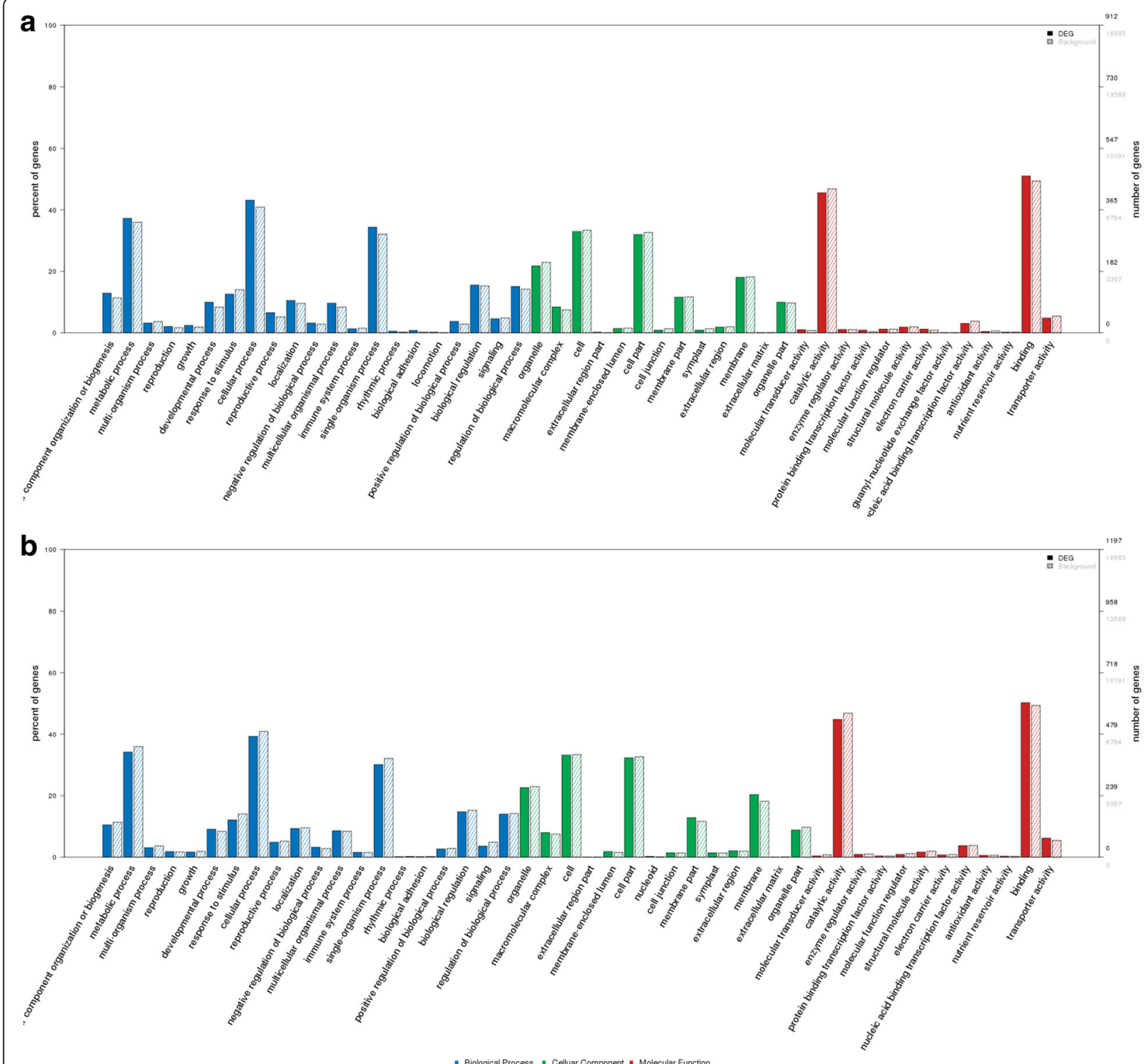

Fig. 3 Gene ontology classification of potential target genes for differentially expressed miRNAs. The $x$-axis indicates the category name of GO annotation. The right $y$-axis indicates the number of unigenes in a category. The left $y$-axis indicates the percentage of a specific category of unigenes in that main category. The solid bars show the target genes of differentially expression miRNAs, while the hollow bars show genes from the $3^{\prime} U T R$ (or mRNA) database. $\mathbf{a}$ Gene ontology classification of the known differential miRNA target genes. $\mathbf{b}$ Gene ontology classification of the novel differential miRNA target genes. Blue, green and red represent three GO ontologies: cellular component, molecular function and biological progress, respectively

increased by 2.9 -fold, 6.1 -fold and 2.0 -fold respectively under UVB treatment compared to the control groups. However, NAD dependent sorbitol dehydrogenase (NAD$S D H)$ was rarely expressed under UVB treatment. Moreover, the expression levels of Pyrophosphate-fructose 6-phosphate 1-phosphotransferase subunit alpha (PFP- $\alpha)$ and Phosphofructokinase (PFK) in hexose pathway were1.8-fold and 1.6-fold higher in UVB group than those in control group (Fig. 8c). Hexose carrier protein (HEX6) showed a 3.2-fold decrease after UVB stimulation (Fig. 8c).
These results indicated that UVB had a major influence on the interconversion and transportation of monosaccharides. The gene information and sequences of primers were listed in Additional file 6: Table S6.

\section{Discussion}

There are many problems in the protected cultivation of peach trees, such as the basic theory and growth/development pattern, the environmental intelligent control, the standardization system with high quality and 


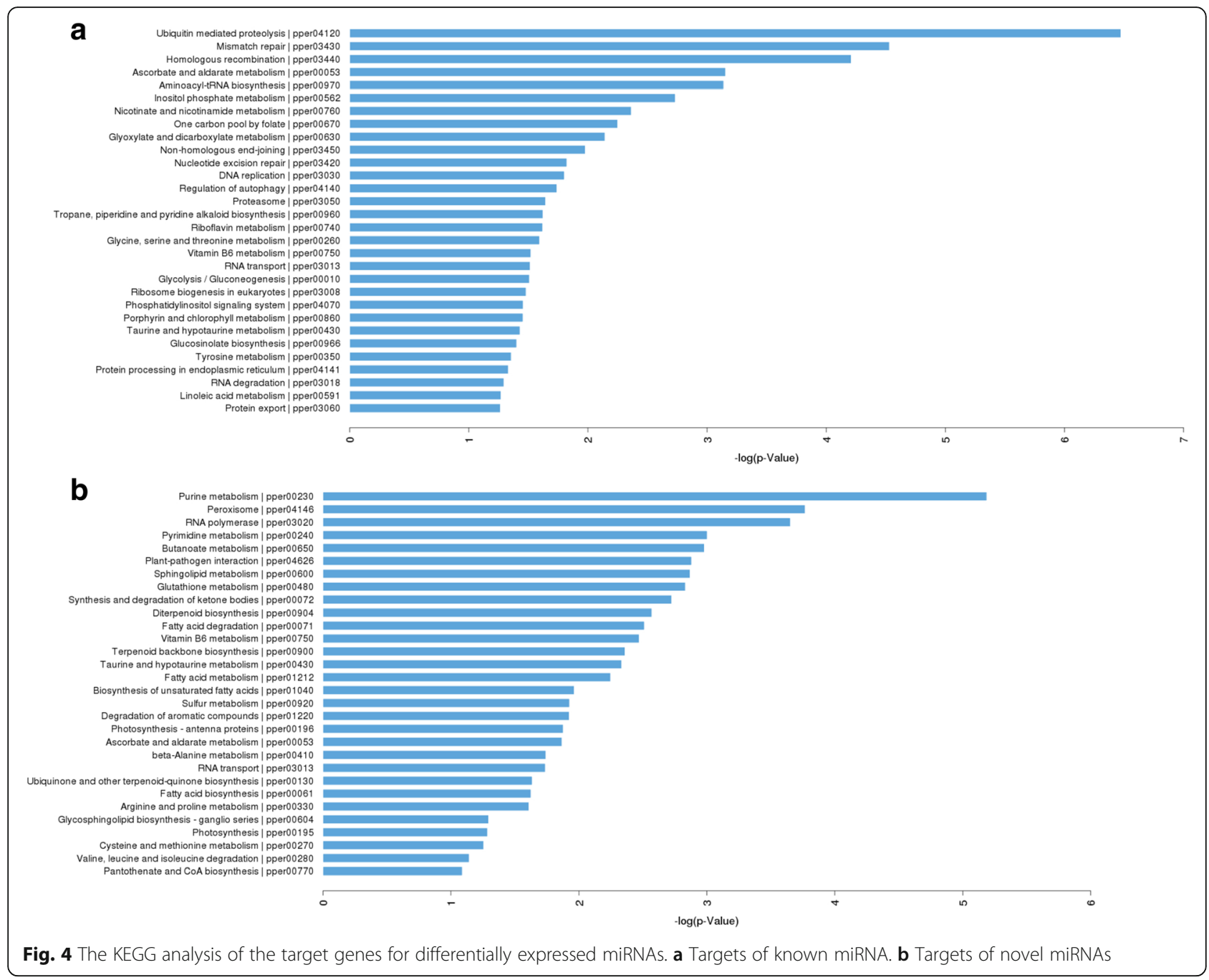

efficiency etc. [38]. It is mainly ascribed to the weak light irradiance and quality, and the quality of fruits in the greenhouse is worse than that in the outdoor cultivation [39]. Our investigation on the regulatory mechanism of complementary UVB will provide significant effects for elucidating the growth and development pattern of $P$. persica, thus increasing the fruit quality.

High-dose UVB may produce phenols, ROS and cause damage to DNA, proteins, and membranes [40-42]. However, low-dose UVB may trigger early adaptation to environment and regulate plants seeding, development and growth such as the induction of alterations in antioxidant status, the regulation of phenylpropanoids, cinnamates, or flavonoids pathways, chlorophyll and pyridoxine biosynthesis pathways [43]. In our previous study, Chen et al. selected three UVB radiation levels and $1.44 \mathrm{Kj} \mathrm{m}^{-2} \mathrm{~d}^{-1}$ showed the most effective function on the improvement of total soluble solid, anthocyanin and the repression of total acid in peach cultivated in greenhouse [44]. Therefore the UVB radiation level (1.44
$\mathrm{Kj} \mathrm{m}^{-2} \mathrm{~d}^{-1}$ ) was applied in this study as the most suitable dose to regulate the growth and fruit quality of $P$. persica in the greenhouse environment.

MiRNAs play important roles in plant response and adaptation to environmental change. Thus, understanding the miRNA-mediated regulatory network of UVB supplement will lay the foundation for unraveling the complex molecular genetic mechanism of positive effects on fruit's agronomic traits improvement. A growing evidences suggested that miRNA-guided gene regulation could play a vital role in plant response to UVB radiation $[42,45,46]$. In the present study, a total of $4.02 \mathrm{M}$ and $3.83 \mathrm{M}$ unique sRNA sequences were obtained from the control and UVB-treatment libraries, respectively, suggesting adequate sequencing depth for further analysis. The majority of total sRNA reads ranged from $18 \mathrm{nt}$ to $30 \mathrm{nt}$ in length (Fig. 1), which was consistent with the typical size for Dicer-derived products [47]. The most abundant length is $21 \mathrm{nt}$ followed by $24 \mathrm{nt}$ which was consistent with previous studies in peach [48-51]. 
Table 2 The comparison of fold change (from sequencing libraries) and expression levels (via qRT-PCR) of typical miRNAs

\begin{tabular}{|c|c|c|c|c|c|c|}
\hline & MiRNA & Source & Target & Annotation & $\begin{array}{l}\text { Sequencing } \\
\text { (Fold-change) }\end{array}$ & $\begin{array}{l}\text { qRT-PCR } \\
\text { (Fold-change) }\end{array}$ \\
\hline \multirow[t]{15}{*}{ Down-regulation } & miR159 & Ptc [27],Ath,Pte [22] & MYB33 & leaf development & - & - \\
\hline & Pp05-28,899-3p & Sequencing & & & 0.47 & - \\
\hline & miR395d & $\begin{array}{l}\text { Sequencing, Ath } \\
\text { [22],Ptc [27] }\end{array}$ & APS,AST68 & $\begin{array}{l}\text { sulfate translocation } \\
\text { and assimilation. }\end{array}$ & 0.5 & 80.75 \\
\hline & miR7122b-5p & Sequencing & HOS & & 0.47 & 17.55 \\
\hline & miR8133-3p & Sequencing & & & 0.32 & 13.93 \\
\hline & miR399a & $\begin{array}{l}\text { Sequencing, Ath } \\
\text { [22],Ptc [27] }\end{array}$ & UBC24 & & 0.18 & 13.18 \\
\hline & miR395e & $\begin{array}{l}\text { Sequencing, Ath } \\
{[22], \text { Ptc [27] }}\end{array}$ & APS,AST68 & $\begin{array}{l}\text { sulfate translocation } \\
\text { and assimilation. }\end{array}$ & 0.5 & 2.89 \\
\hline & miR1511 & Ppe [37] & & unique & - & 2.31 \\
\hline & miR171c & Ath [52] & $\mathrm{SCL}$ & chlorophyll synthesis & - & 2.31 \\
\hline & miR399b & Sequencing & & & 0.29 & 2.09 \\
\hline & miR3627-3p & Ppe [58] & & TCA, EMP & - & 1.61 \\
\hline & miR393a & Ath,Pte [22] & $\begin{array}{l}\text { AFB2,TIR1, } \\
\text { SCF }\end{array}$ & $\begin{array}{l}\text { Antibacterial Resistance, } \\
\text { abiotic stress tolerance }\end{array}$ & - & 1.41 \\
\hline & miR5072 & Ppe [37] & & alternative reference & - & 1.25 \\
\hline & miR166a & Ath,Pte [22] & HD-ZIP & abiotic stress tolerance & - & 1.05 \\
\hline & miR156a & Ath,Pte [22] & SPL & abiotic stress tolerance & - & 1.05 \\
\hline Reference & miR5059* & Ppe [37] & & reference* ${ }^{*}$ & - & 1 \\
\hline \multirow[t]{15}{*}{ Up-regulation } & miR397 & Sequencing & Laccase & & 2.42 & 1.07 \\
\hline & miR160a & Ath,Pte [22] & ARF17 & Leaf development & - & 1.24 \\
\hline & miR402 & Ppe [37] & & abiotic stress tolerance & - & 1.28 \\
\hline & miR319a & Ath [21] & & flowing time & - & 1.75 \\
\hline & Pp03-19,842-3p & Sequencing & & & 5.23 & 2.04 \\
\hline & miR398a-3p & Ath,Pte [22] & $\operatorname{CSD} 1,2$ & $\begin{array}{l}\text { protection from } \\
\text { oxidative stress }\end{array}$ & - & 2.09 \\
\hline & miR6260 & Ppe [37] & & unique & - & 2.31 \\
\hline & miR171d-3p & Sequencing & & & 5.1 & 2.43 \\
\hline & Pp03-22,312-5p & Sequencing & & & - & 3.77 \\
\hline & Pp03-22,312-3p & Sequencing & & & 2.42 & 4.15 \\
\hline & miR6263 & Ppe [37] & & unique & 4.67 & 5.21 \\
\hline & miR3627-5p & Sequencing & & & 6.02 & 5.24 \\
\hline & Pp06-35,148-3p & Sequencing & & & 2.57 & 6.09 \\
\hline & miR398a-5p & Ath,Pte [22] & $\operatorname{CSD} 1,2$ & $\begin{array}{l}\text { protection from } \\
\text { oxidative stress }\end{array}$ & - & 6.67 \\
\hline & Pp06-35,148-5p & Sequencing & & & 4.75 & 11.99 \\
\hline
\end{tabular}

Abbreviations: Ath Arabidopsis thaliana, Ptc Populus trichocarpa, Pte Populus tremula, Ppe Prunus persica

In our study, the expression levels of 2 known miRNAs were highly up-regulated (miR171d-3p, miR3627-5p) and 6 known miRNAs showed significant down-regulation (miR395d, miR395e, miR399a, miR399b, miR7122b-5p, miR8133-3p). These miRNAs were predicted to be involved in distinct metabolic pathways.

MiR171c was predicted to target SCL6, SCL22 and $S C L 27$, a family of transcription factors which were involved in the morphogenesis, proliferation of meristematic cells, polar organization and chlorophyll synthesis [52-54]. Further study found that its target gene tomato (Solamum lycopersicum) gras transcription factor gene (SlGRAS24) impacts multiple agronomical traits, such as plant height, flowering time, leaf architecture, lateral branch number, root length, fruit set and development, via regulating gibberellin and auxin 


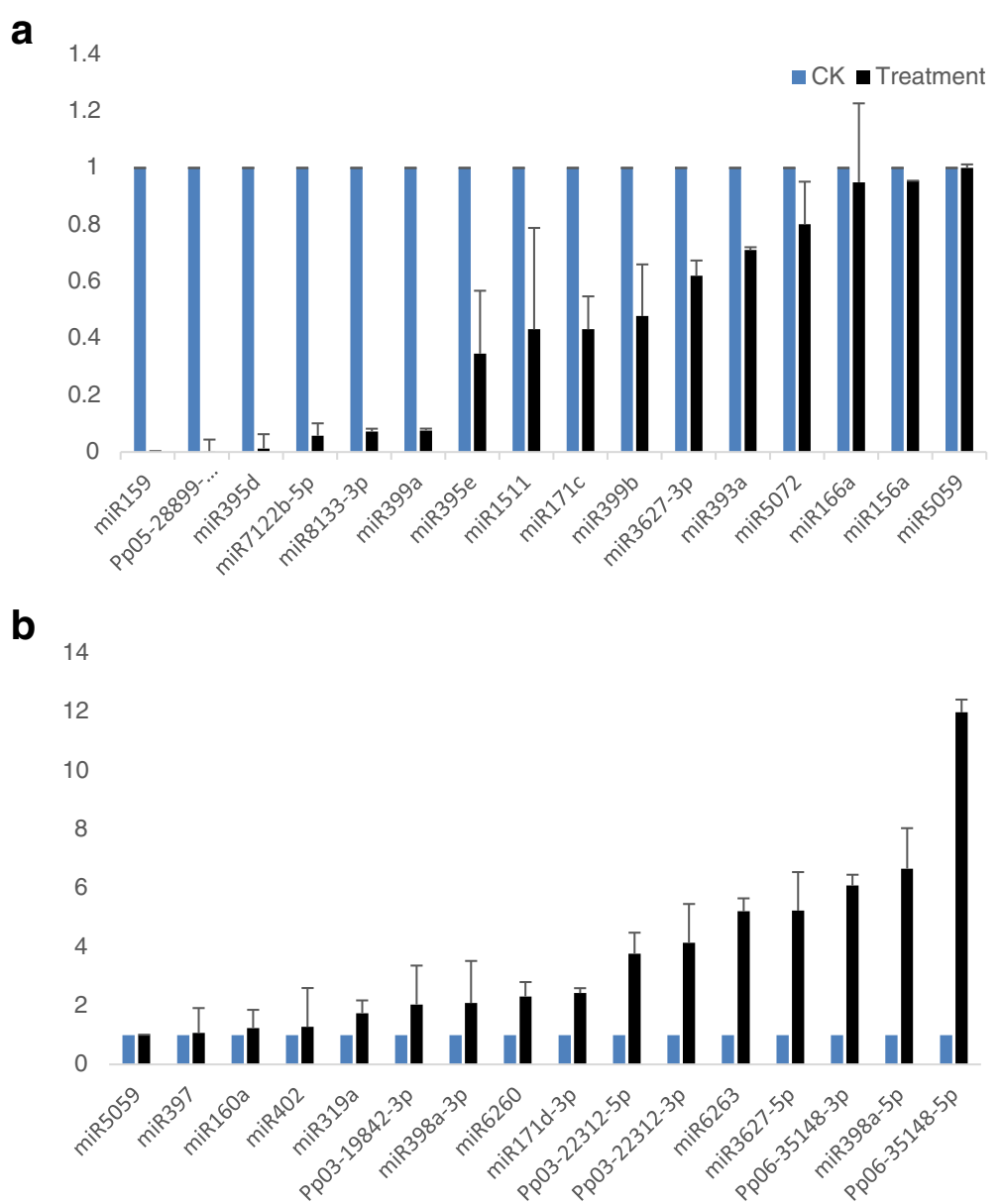

Fig. 5 Relative expression levels of the selective UVB-responsive miRNAs by qRT-PCR analysis. a Down-regulation. $\mathbf{b}$ Up-regulation

homeostasis [55, 56]. It is indicated that the UVBresponsive miRNA171 plays an important role in regulating the growth and development of plant. In the present study, we investigated the potential relation between miR171c and chlorophyll synthesis. The content of chlorophyll was gradually increased during the whole development period under UVB treatment, which was in accordance with the studies by Chen [44]. Although previous reports showed that miRNA171 was up-regulated under light [57], our results found that miRNA171c was less expressed after UVB stimulation. Further analysis on genes involved in miR171-SCL model showed that $S C L$ and PORC were up-regulated and down-regulated respectively, which was in accordance with this model. PORC had positive effects as an upstream gene of chlorophyll synthetic pathway. However, our results showed an opposite regulation pattern between PORC and chlorophyll content. Interestingly, the expression levels of Chlorophyll a-b binding protein $(C B R)$ and Red chlorophyll catabolite reductase $(P C C R)$ (genes involved in chlorophyll degradation) had no change after UVB treatment, while the $C H L G$ was up-regulated by 1.6 -fold.
According to these results, we presumed that the increase of chlorophyll content under UVB might be not only related with miR171-SCL model but also regulated by non miR171-SCL pathway like the regulation of CHLG. Further verification is needed to illustrate the regulatory mechanism of chlorophyll metabolism under UVB.

A conserved miRNA family (miR3627) was reported only in five species (Solanum tuberosum, Malus domestica, Populus trichocarpa, Citrus trifolia, and Prunus persica), and was identified as a chilling responsive miRNA in $P$. persica [58]. In our study, miRNA3627-5p was upregulated under UVB treatment, and we found an interesting physiological phenomenon that the germination rate of treatment group (89.2\%) was $12 \%$ higher than the CK group (77.5\%), which occurred 8 months after the termination of UVB treatment. It implied that UVB radiation may have a long-term and sustainable influence on plants via modification called "UVB memory" [59], and this phenomenon involved a series of miRNAs such as miR3627-5p. Bioinformatics analysis of miR3627-5p in our libraries showed that it had 415 target genes which referred to many pathways such as 


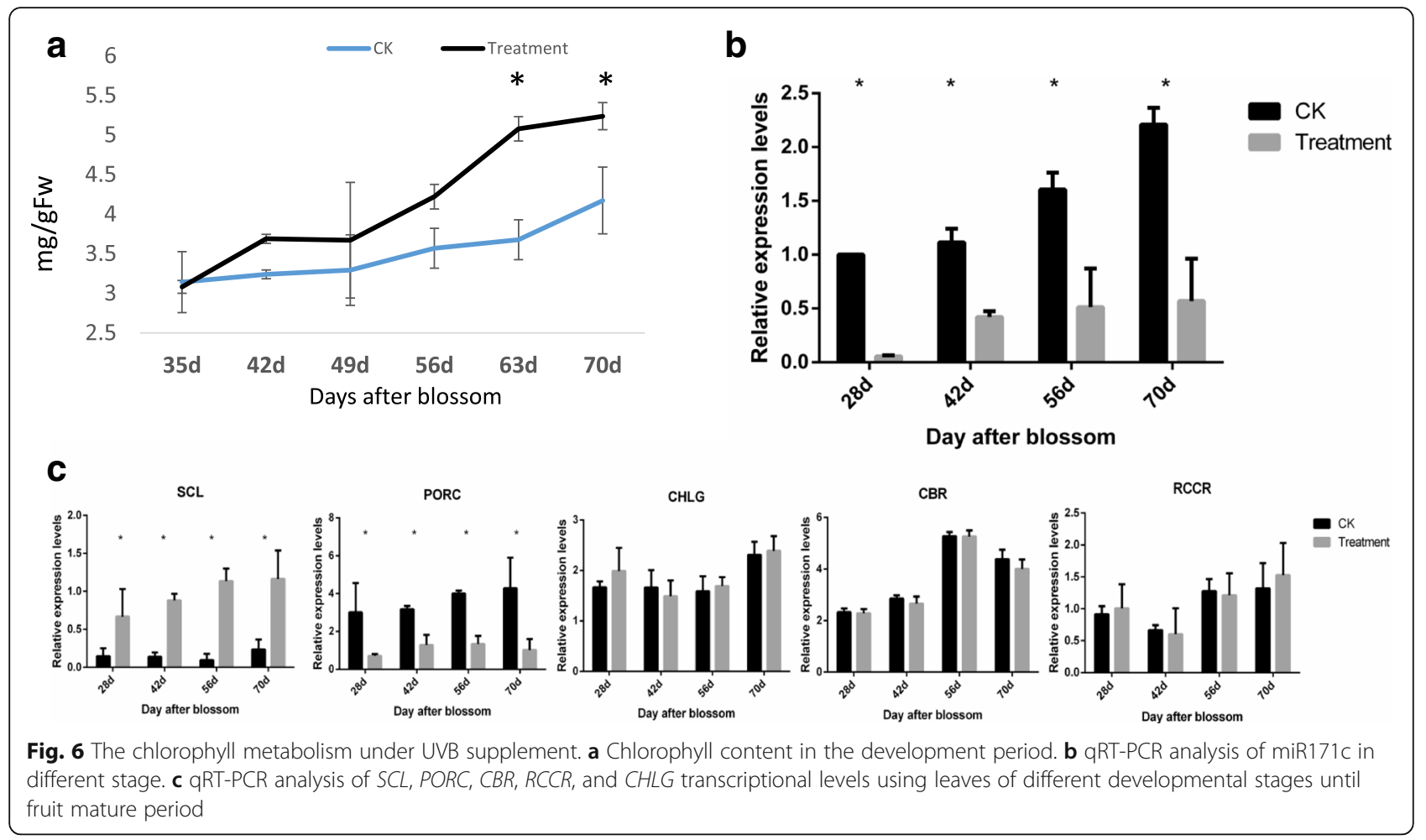

metabolic, protein and amino acid metabolism, RNA transport and circadian rhythm. However, the molecular mechanism of miR3627-5p regulation in chilling still needs more experimental studies.

The target genes of miR3627-5p: ppa025787mg, ppa007623mg, ppa016917mg, ppa021860mg were involved in pentose and glucuronate interconversions, starch and sucrose metabolism. Besides, miR3627-5p target gene ppa007934mg is involved in carbon metabolism and TCA cycle. The expression levels of these five target genes were all down-regulated (Additional file 7: Figure S1), which were consistent with the up-regulation of miR3627-5p. Also the predicted target genes of novel miRNA Pp03_22,312-5p (upregulated) were involved in sugar metabolism. This indicated that miRNA may participate in the formation of fruit sweetness, an essential

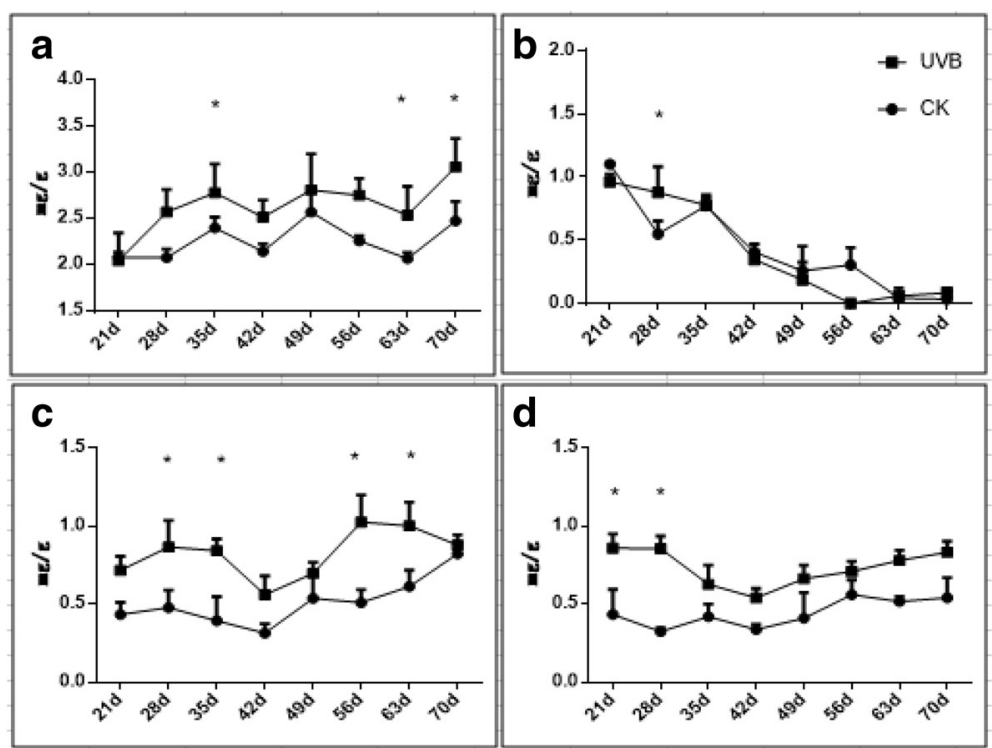

Fig. 7 Comparison of the contents of carbohydrates in leaves at mature stage in CK and UVB group. a Sorbitol. b Sucrose. c Glucose. d Fructose 


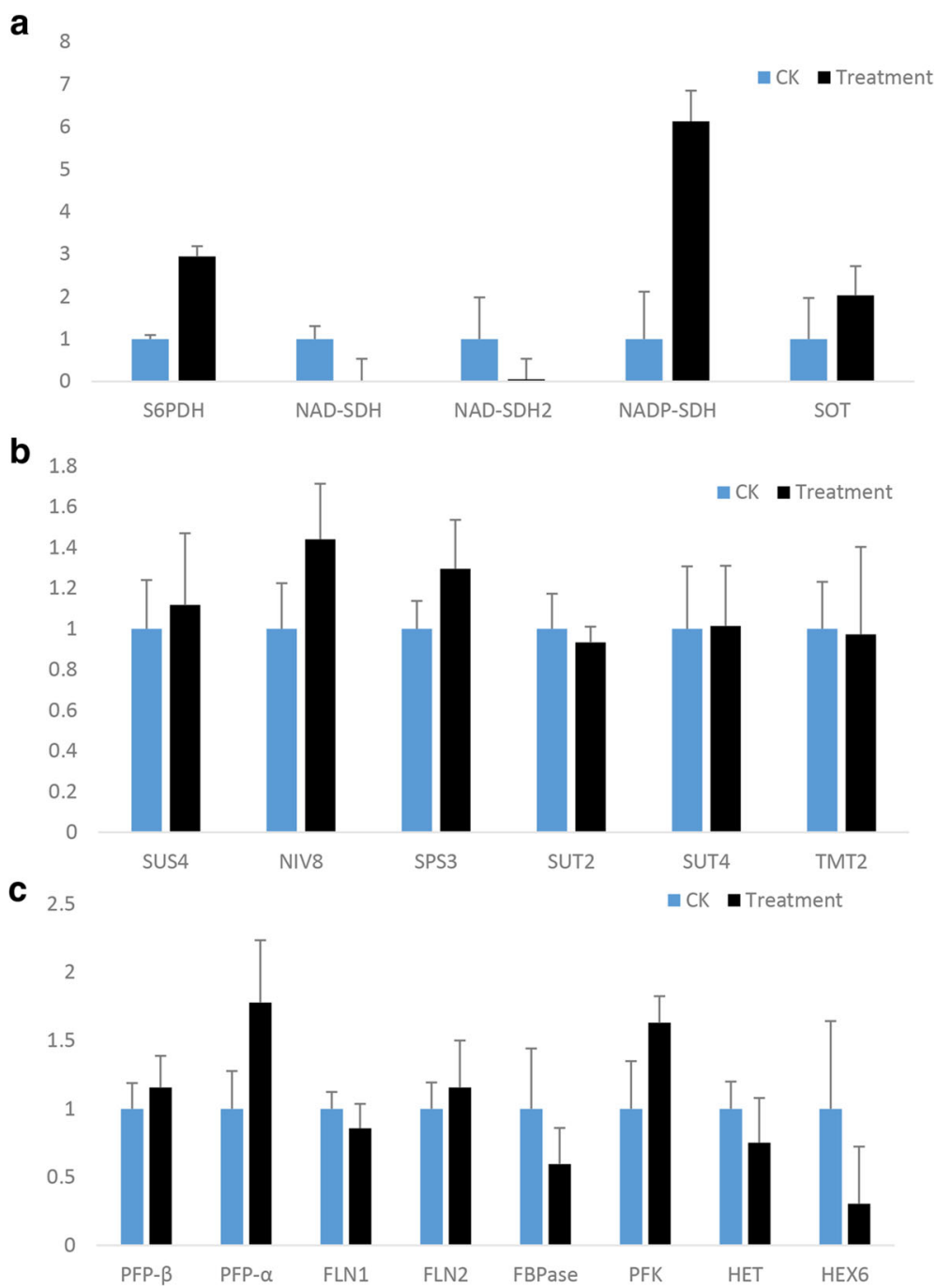

Fig. 8 qRT-PCR analysis of key genes which related to sugar metabolism. a S6PDH, NAD-SDH, NAD-SDH2, NADP-SDH, and SOT which are related to sorbitol metabolism. b SUS4, NIV8, SPS3, SUT2, SUT4, and TMT2 which related to sucrose metabolism. c PFP- $\beta$, PFP- $\alpha$, FLN1, FLN2, FBPase, PFK, HET, and HEX6 which related to Hexose metabolism

characteristic of fruit quality which was in accordance with previous reports [60].

Different sugar components in leaves were analyzed by High Performance Liquid Chromatography (HPLC) and we found that the carbohydrate contents changed variously under UVB treatment (Fig. 7). Accordingly, we speculated some UVB-responsive miRNAs which targeted sugar-metabolizing pathway, such as miR3627$5 p$. Further qRT-PCR showed relative expression of the key genes in different sugar metabolic pathways (Fig. 8). Sorbitol is the main form of sugar in Rosaccae leaves and is transferred to fruits for the storage of carbohydrates in the mature stage. The content of sorbitol in our study was gradually increased with the developmental process, which was assistant with previous reports [61]. qPCR results showed that sorbitol-related genes were distinctly expressed with UVB treatment. The relative expression levels of $S 6 P D H$ was remarkably upregulated in UVB-group, indicating the increase of $S 6 P D H$ activities and therefore stimulating the synthesis of sorbitol. $N A D-S D H 1$ and $N A D-S D H 2$ were downregulated while the levels of $N A D P-S D H$ were increased after UVB treatment. This suggested that the plants restricted $N A D-S D H s$ expression to reduce sorbitol degradation while increased $N A D P-S D H$ transcripts for the synthesis of fructose from sorbitol under UVB treatment. SOT was up-regulated, responsible for more active transportation of sorbitol, which accorded with the increase of sorbitol contents.

The content of sucrose did not change obviously during the continuous growth period, which could be explained by the slight change of expression levels of 
genes involved in sucrose metabolism, such as Sucrose synthase (SUS), Sucrose transporter (SUT), Tonoplast monosaccharide transporter (TMT) etc. In hexose pathway, the crucial genes PFP- $a$ and $P F K$ were up-regulated while Fructose-1,6-bisphosphatase (FBPase) and HEX6 were down-regulated, implying the UVB treatment had an influence on hexose metabolism.

In our study, the UVB treatment led to different expression patterns of genes related with sugar metabolism. Previous research have shown that the regulation was mainly mediated by miRNA. Our results were essentially in agreement with these reports, and more investigations on functional verification need to be performed.

\section{Conclusions}

In this study, we constructed 2 miRNA libraries for lowdose UVB radiation groups and control groups of $P$. persica in greenhouse. A total of 164 known and 109 novel miRNAs were identified. In brief, 8 miRNAs were highly up-regulated and 7 miRNAs were significantly downregulated in the UVB treatment groups, which were mainly predicted to be targeted in signal transduction, carbohydrate metabolism and stress response etc. Combined with qRT-PCR tests and the measurement of the related metabolites, our results showed that low-dose UVB radiation could regulate the expression patterns of some miRNAs e.g. miR3627-5p and Pp_22,312, and cause the expression levels of genes in carbohydrate (sorbitol, fructose, and glucose etc.) and chlorophyll pathway, and therefore indirectly affect sugar contents and fruit quality (Fig. 9). Our study provided a comprehensive database of miRNA for $P$. persica and a theoretical basis for further investigations of the function of miRNA in regulating the biological features of peach in greenhouse.

\section{Methods}

Plant material and tissue collection

The experiment was carried out on 7-year-old peach trees (Prunus persica var. nectarine Zhongyou No.5) cultivated in experimental station of Shandong Agriculture university, Taian, China. The trees were treated with $1.44 \mathrm{Kj} \mathrm{m} \mathrm{m}^{-2} \mathrm{~d}^{-1} \mathrm{UVB}$ radiation during the whole growing period. UVB was provided by the dedicated UV lamp of $40 \mathrm{~W}, 297 \mathrm{~nm}$ (Nanjing Kazhi), hanging at the position of $1.5 \mathrm{~m}$ above the plants. UVB-type singlechannel UV irradiator (Beijing Normal University Photoelectric Instrument Factory) equipped with $297 \mathrm{~nm}$ probe was used to determine the UVB radiation dose of $1.44 \mathrm{Kj} \mathrm{m}^{-2} \mathrm{~d}^{-1}$. The function leaves within the range of $80-120 \mathrm{~cm}$ below the lamp were selected. The on/off time of UV light was controlled through the electronic automatic control device, from 7 days after blossom to the fruit mature stage. UV light was kept on from 9 h30 to 10 h30 every day and stopped at cloudy, rainy and snowy days. Function leaves were sampled on the 7th day after blossom and every week after, until the mature period. These samples were washed with DEPCtreated $\mathrm{H}_{2} \mathrm{O}$, immediately frozen in liquid nitrogen and stored at $-80{ }^{\circ} \mathrm{C}$ until use. The function leaves of fruit mature stage were selected for high-quality deepsequencing.

\section{Small RNA isolation and Illumina sequencing}

Total RNA in peach was isolated using the mirVan miRNA Isolation kit (Ambion; Thermo Fisher Scientific, USA) and purified using the miRNeasy Mini kit (Qiagen, Germany), following the manufacturer's instructions. RNA was quantified using a spectrophotometer (NanoDrop, Thermo Fisher Scientific, USA). Purified RNA was frozen in liquid nitrogen and then stored at $-80{ }^{\circ} \mathrm{C}$ until required.

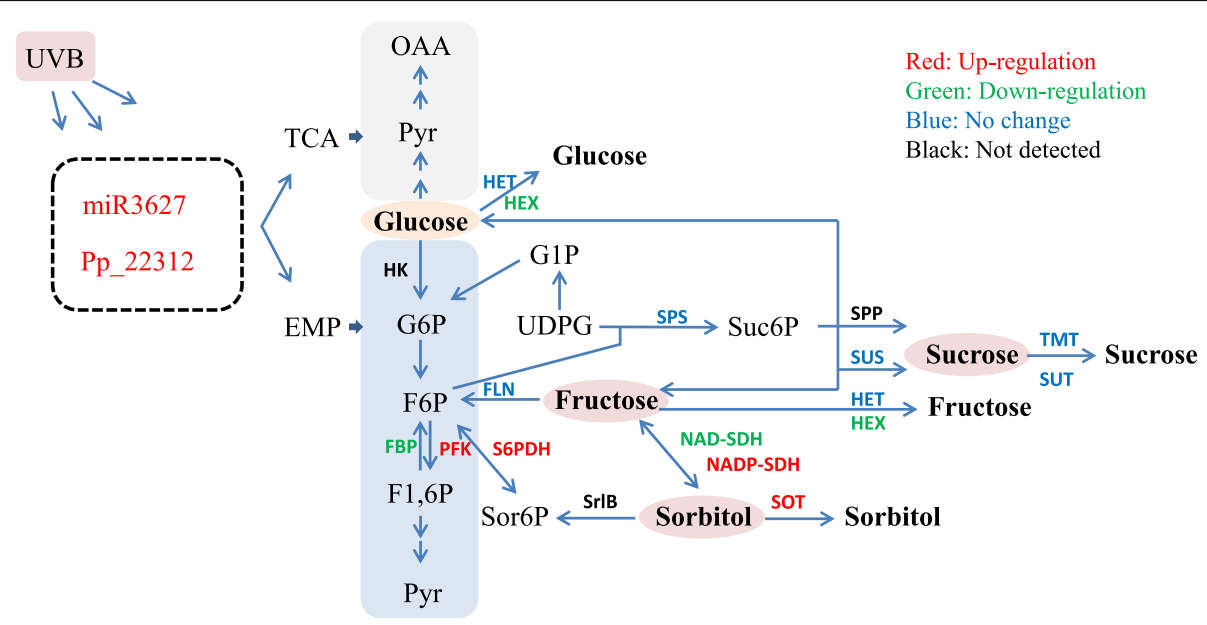

Fig. 9 The schemetic of potential carbohydrate pathways regulated by miRNA under UVB radiation in greenhouse. Red: Genes were up-regulated transcriptional levels under UVB; Green: Down-regulation; Blue: No change; Black: Not detected by qRT-PCR 
We constructed an RNA library using the NEBNext Ultra RNA Library Prep kit for Illumina (New England Biolabs, USA). There were four steps: Firstly, total RNA (approx. $1 \mu \mathrm{g}$ ) was spliced into shorter fragments (200-500 bp) in the NEBNext First Strand Synthesis Reaction Buffer and the fragments were used to produce the double-stranded cDNA; secondly, the cDNA was end-repaired and ligated with Illumina-specific adaptors; thirdly, we used $200 \mathrm{bp}$ inserts from the library and selected suitable fragments for PCR amplification; last, we performed PCR using Phusion High-Fidelity DNA polymerase (New England Biolabs, USA) and purified the products with a QIAquick Nucleotide Removal kit (Qiagen, Germany). Then we sequenced the new RNA library on an Illumina HiSeq 2500 system using $2 \times 150$ base pairs paired-end sequencing.

\section{Analysis of sequencing data}

Clean reads were obtained from raw reads after removing low-quality and adapter reads. SOAP software was used for the mapping of clean reads to the peach genome. The non-coding RNAs, including rRNAs, scRNAs, snoRNAs, snRNAs, and tRNAs deposited in the NCBI GenBank database and Rfam (11.0) database, were removed. We also excluded the small RNAs corresponding to the exons and introns of mRNA and repeat sequences. The remaining sRNA sequences were aligned to the miRBase 21 database, with a maximum of two mismatches, to identify known miRNAs in $P$. persica. The obtained sequences were used to predict hairpin structures using the perpl program. The remaining unannotated sRNAs were used to predict novel miRNAs using Mireap software [62].

\section{Target prediction of miRNAs and functional analysis}

Target prediction of miRNAs followed rules referring to Allen et al. [63]: a. stwo adjacent mismatches in the miRNA/target duplex; b. $\leq$ four mismatches between the sRNA and target gene; c. $\leq 2.5$ mismatches at positions 1-12 of the $5^{\prime}$-miRNA/target duplex; d. no mismatches at $10-11$ of the miRNA/target duplex; e. no adjacent mismatches at 2-12 of the miRNA/target duplex; $f$. the minimum free energy (MFE) of the miRNA/target duplex should be $75 \%$ of the MFE bound to the perfect complement. Target genes were searched using peach genome information. To better understand the roles of miRNAs in peach under low-dose UVB treatment, the potential target functions were annotated using the Gene Ontology and KEGG pathway database.

\section{Differential expression analysis of miRNAs}

The miRNA reads were used to analyze differential expression and determine significant differences between the control and treatment libraries. The frequency of
miRNAs was normalized to one million to reduce potential errors before calculating the fold-change, $P$ value and ratio. Normalized expression $=($ actual miRNA counts/total counts of clean reads) $\times 1,000,000$. Foldchange $=\log 2$ (miRNA normalized read counts in the treatment library/ in the control library).

A fold change larger than 1 or less than -1 and a $P$-value less than 0.01 suggested the highly significant difference in the miRNA expression between two libraries. When the fold-change was greater than 1 or less than -1 and the P-value was between 0.01 and 0.05 , the expression of the miRNA was significantly different between the two libraries. The ratio of miRNA normalized read counts in treatment library/in control library was used to determine changes in the expression of an miRNA in the treatment samples compared with the control samples. When the ratio was more than 2 , the miRNA was indicated as up-regulated, and when the ratio was less than $1 / 2$, the miRNA was down-regulated [64].

\section{Relative expression of miRNA and target genes}

qRT-PCR was performed to verify the expression levels of identified miRNAs and targets genes using the IQ5 Quantitative Real-time PCR Detection System (Bio-Rad, California, USA) with the $\mathrm{SYBR}^{\oplus}$ PrimeScript $^{\mathrm{Tm}}$ miRNA RT-PCR Kit (TaKaRa, Dalian, China). The reactions were performed in a total volume of $25 \mu \mathrm{L}$ containing $2.0 \mu \mathrm{L}$ of diluted cDNA $(100 \mathrm{ng} / \mu \mathrm{L}), 1 \mu \mathrm{L}$ of each primer $(10 \mu \mathrm{M})$, and $12.5 \mu \mathrm{L}$ of SYBR Green premix Ex Taq II with the following reaction conditions: $95{ }^{\circ} \mathrm{C}$ for $30 \mathrm{~s}$, followed by 40 cycles of $95{ }^{\circ} \mathrm{C}$ for $5 \mathrm{~s}$ and $60{ }^{\circ} \mathrm{C}$ for $20 \mathrm{~s}$, then dissociation curve with $95{ }^{\circ} \mathrm{C}$ for $60 \mathrm{~s}, 55^{\circ} \mathrm{C}$ for $30 \mathrm{~s}$ and $95{ }^{\circ} \mathrm{C}$ for $30 \mathrm{~s}$. The reference genes for qRT-PCR of miRNA and target genes were miR5059 and beta-actin, respectively $[65,66]$. Each sample was processed in triplicate. All validated primer sequences of miRNAs/target genes are listed in Table S5 and Table S6.

\section{Metabolites analysis by HPLC}

Four sugar components: sucrose, sorbitol, glucose and fructose of leaves, were analyzed according to the method of Karkacier et al. [67]. In a mortar pre-cooled in the $-20{ }^{\circ} \mathrm{C}$ refrigerator, $100 \mathrm{mg}$ of fresh leaves were ground with liquid nitrogen and extracted with $1 \mathrm{~mL}$ NANO pure water into a $2 \mathrm{ml}$ tube. The tubes were then vigorously shaken for $15 \mathrm{~s}$, sonicated for $15 \mathrm{~min}$ and centrifuged at $12,000 \mathrm{rpm}$ for $15 \mathrm{~min}$. The supernatant was sterilized by filtering through a $0.45 \mu \mathrm{m}$ membrane filter and stored at $-20{ }^{\circ} \mathrm{C}$ prior to sugar components' measurement using HPLC. The HPLC system was programmed to inject $50 \mu \mathrm{L}$ crude extracts automatically. Online detection was performed using a Waters 410 differential refractrometer detector and the data were analyzed by Oirigin75 software. The whole 
program used a MetaCarb $87{ }^{\circ} \mathrm{C}$ equipped with a guard column as the analytical column, and the deionized water as the mobile phase with a $0.5 \mathrm{~mL} \mathrm{~min}{ }^{-1}$ flow rate. Glucose, sorbitol, fructose and sucrose purchased from company were used as standards [68].

\section{Chlorophyll content}

Function Leaves were taken every 7 days after flowering to measure chlorophyll content via spectrophotometry. The maximum UV absorption wavelength of chlorophyll a and chlorophyll b is $645 \mathrm{~nm}$ and $663 \mathrm{~nm}$ respectively. The total chlorophyll content was analyzed with the following formula [69]:

$$
C_{T}=C_{a}+C_{b}=20.29 A_{645}+8.05 \mathrm{~A}_{663} \text {. }
$$

\section{Additional files}

Additional file 1: Table S1. The summary of known miRNAs prediction and expression in control and UVB supplement libraries. (PDF $250 \mathrm{~kb}$ )

Additional file 2: Table S2. The summary of novel miRNAs prediction and expression in control and UVB supplement libraries. (PDF $162 \mathrm{~kb}$ )

Additional file 3: Table S3. Details of targets genes and their annotation, GO classification, and KEGG pathway for the known miRNAs. (PDF $2499 \mathrm{~kb}$ )

Additional file 4: Table S4. Details of targets genes and their annotation, GO classification, and KEGG pathway for the known miRNAs. (PDF $2823 \mathrm{~kb}$ )

Additional file 5: Table S5. Primers for qRT-PCR verification of miRNAs. (PDF $17 \mathrm{~kb}$ )

Additional file 6: Table S6. The names, Genbank IDs, involved pathways of verified target genes and their primers for qRT-PCR tests. (PDF $79 \mathrm{~kb}$ )

Additional file 7: Figure S1. qRT-PCR analysis of five target genes predicted for miR3627-5p. Beta-actin was the internal control. Each experiment was performed with three biological replicates. (PDF $66 \mathrm{~kb}$ )

\section{Abbreviations}

CBR: Chlorophyll a-b binding protein; CHLG: Chlorophyll synthase; COP1: Constitutively photomorphogenic 1; FBPase: Fructose-1,6bisphosphatase, chloroplastic; FLN1: Fructokinase-like 1; FLN2: Fructokinaselike 2; HET: Hexose transporter; HEX6: Hexose carrier protein; HPLC: High Performance Liquid Chromatography; HY5: Elongated hypocotyl 5; NADPSDH: NADP-sorbitol dehydrogenase; NAD-SDH: NAD-sorbitol dehydrogenase; NAD-SDH2: NAD-sorbitol dehydrogenase 2; NIV8: Neutral invertase 8; PFK: Phosphofructokinase; PFP-a: Pyrophosphate-fructose 6-phosphate 1-phosphotransferase subunit alpha; PFP- $\beta$ : Pyrophosphate-fructose 6-phosphate 1-phosphotransferase subunit beta; PORC: Pchlide oxidoreductase C; RCCR: Red chlorophyll catabolite reductase; S6PDH: Sorbitol -6- phosphate dehydrogenase; SCL: Scarecrow-like protein; SIGRAS24: A tomato (solamum lycopersicum) GRAS transcription factor gene; SOT: Sorbitol transporter; SPS: Sucrose phosphate synthase; SUS4: Sucrose synthase 4; SUT2: Sucrose transporter 2; SUT4: Sucrose transporter 4; TMT2: Tonoplast monosaccharide transporter; UVB: Ultraviolet radiation B; UVR8: UV resistance locus 8

\section{Acknowledgements}

We thank WX in the lab for providing the trees and BBW and ZJZ for DNA extraction. We thank GW from the CapitalBio Technology for sequencing performed and bioinformatics support. We are grateful to all co-authors who participated in the studies mentioned in the text that were published by our groups. All authors declared no conflict of interest.

\section{Funding}

This work was supported by the National Natural Science Foundation of China [Grant number 31601706], Natural Science Foundation of Shandong Province [Grant number ZR2016CM09] and Science and Technology Innovation Team of Shandong Agriculture University-Facility Horticulture Advantages Team (SYL2017YSTD07). The funding institutions had no direct role in study design, sample collection, analysis, and interpretation of date, nor in manuscript writing Annual reports were submitted to the funding institutions tracking the progress of the projects.

\section{Availability of data and materials}

The dataset supporting the conclusions of this article is available in the NCBI database, with the BioProject: ID PRJNA391378 and Locus tag prefix CEW84.

\section{Authors' contributions}

SXL and DML conceived and designed the research. SXL performed the experiments and wrote the manuscript. SXL and ZRS analyzed the data, and ZRS revised the intellectual content of this manuscript. XLF and LL contributed in the retrieval of genes and the analysis of qRT-PCR results. WX cultivated the plant materials and helped to analyze the physiological data. MC and MYS contributed in designing GRT-PCR primers. DML and DSG supervised the project as co-correspondence. All authors have read and approved the final manuscript.

\section{Ethics approval and consent to participate}

The peach trees and fruits were cultivated and collected in the No. 15 greenhouse of Scientific and Technological Innovation Park in Shandong Agriculture University. The authors declared the compliance with institutional, national and international guidelines. The experiment was environmentally friendly and had no negative effects on the local ecosystem.

\section{Consent for publication}

Not applicable.

\section{Competing interests}

The authors declare that they have no competing interests.

\section{Publisher's Note}

Springer Nature remains neutral with regard to jurisdictional claims in published maps and institutional affiliations.

\section{Author details}

${ }^{1}$ College of Horticulture Science and Engineering, Shandong Agricultural University, Tai'an 271018, People's Republic of China. ${ }^{2}$ State Key Laboratory of Crop Biology, Shandong Agricultural University, Tai'an 271018, People's Republic of China. ${ }^{3}$ Key Laboratory of Experimental Marine Biology, Institute of Oceanology, Chinese Academy of Sciences, Qingdao 266071, People's Republic of China. ${ }^{4}$ Laboratory for Marine Biology and Biotechnology, Qingdao National Laboratory for Marine Science and Technology, Qingdao 266237, People's Republic of China.

Received: 27 May 2017 Accepted: 23 November 2017 Published online: 02 December 2017

\section{References}

1. Kami C, Lorrain S, Hornitschek P, Fankhauser C. Light-regulated plant growth and development. Curr Top Dev Biol. 2010;91:29-66.

2. Lidon FJC, Teixeira M, Ramalho JC. Decay of the chloroplast pool of ascorbate switches on the oxidative burst in UV-B-irradiated rice. J Agron Crop Sci. 2012;198:130-44.

3. Pitzschke A, Forzani $\mathrm{C}$, Hirt $\mathrm{H}$. Reactive oxygen species signaling in plants. Antioxid Redox Signal. 2006:8:1757-64.

4. Gill SS, Tuteja N. Reactive oxygen species and antioxidant machinery in abiotic stress tolerance in crop plants. Plant Physiol Biochem. 2010:48:909-30.

5. Jenkins Gl. Signal transduction in responses to UVB radiation. Annu Rev Plant Biol. 2009:60:407-31.

6. Brosche M, Strid A. Molecular events following perception of ultraviolet-B radiation by plants: UVB induced signal transduction pathways and changes in gene expression. Physiol Plant. 2003;117:1-10. 
7. Ballare CL, Caldwell MM, Flint SD, Robinson SA, Bornman JF. Effects of solar ultraviolet radiation on terrestrial ecosystems. patterns, mechanisms, and interactions with climate change. Photochem Photobiol Sci. 2011;10:226-41.

8. Li FR, Peng SL, Chen BM, Hou YP. A meta-analysis of the responses of woody and herbaceous plants to elevated ultraviolet-B radiation. Acta Oecol. 2010;36:1-9.

9. Deckmyn G, Gaeyenberghs E, Ceulemans R. Reduced UV-B in greenhouses decreases white clover response to enhance $\mathrm{CO}_{2}$. Environ Exp Bot. 2001;46(2):109-17.

10. Rizzini L, Favory JJ, Cloix C, Faggionato D, O'Hara A, Kaiserli E, Baumeister R, Schäfer E, Nagy F, Jenkins Gl, et al. Perception of UV-B by the Arabidopsis UVR8 protein. Science. 2011;332(6025):103-6.

11. Christie JM, Arvai AS, Baxter KJ, Heilmann M, Pratt AJ. Plant UVR8 photoreceptor senses UVB by tryptophan-mediated disruption of crossdimer salt bridges. Science. 2012;335:1492-6.

12. Wu D, Hu Q, Yan Z, Chen W, Yan C. Structural basis of ultraviolet-B perception by UVR8. Nature. 2012;484:214-9.

13. Heijde M, Ulm R. UVB photoreceptor-mediated signaling in plants. Trends Plant Sci. 2012:17:230-7.

14. Yi C, Deng XW. COP1-from plant photomorphogenesis to mammalian tumorigenesis. Trends Cell Biol. 2005;15:618-25.

15. Saijo Y, Sullivan JA, Wang H, Yang J, Shen Y. The COP1-SPA1 interaction defines a critical step in phytochrome A-mediated regulation of HY5 activity. Genes Dev. 2003;17:2642-7.

16. Osterlund MT, Hardtke CS, Wei N, Deng XW. Targeted destabilization of HY5 during light-regulated development of Arabidopsis. Nature. 2000;405:462-6.

17. Jones-Rhoades MW, Bartel DP, Bartel B. MicroRNAs and their regulatory roles in plants. Annu Rev Plant Biol. 2006;57:19-53.

18. Ramachandran V, Chen X. Small RNA metabolism in Arabidopsis. Trends Plant Sci. 2008:13:368-74.

19. Voinnet O. Origin, biogenesis, and activity of plant microRNAs. Cell. 2009; 136:669-87.

20. Chen X. MicroRNA biogenesis through Dicer-like 1 protein functions. Proc Natl Acad Sci U S A. 2004;101:12753-8.

21. Sunkar R, Li Y, Jagadeeswaran G. Functions of microRNAs in plant stress responses. Trends Plant Sci. 2012;17:196-203.

22. Sunkar R, Chinnusamy V, Zhu J, Zhu JK. Small RNAs as big players in plant abotic stress responses and nutrient deprivation. Trends Plant Sci. 2007:12:301-9.

23. Pérez-Quintero AL, Quintero A, Urrego O, Vanegas P, López C. Bioinformatic identification of cassava miRNAs differentially expressed in response to infection by Xanthomonas axonopodis pv. manihotis. BMC Plant Biol. 2012;12:1-11.

24. Wang Z, Niu L. Peach industry status and recommendations. Fruit Growers Friend (in Chinese). 2012;11:37-8.

25. Shulaev V, Korban SS, Sosinski B, Abbott AG, Aldwinckle HS, Folta KM, Lezzoni A, Main D, Arus P, Dandekar AM, et al. Multiple models for Rosaceae genomic. Plant Physiol. 2008;147(3):985-1003.

26. Verde I, Abbott AG, Scalabrin S, Jung S, Shu S, Marroni F, Zhebentyayeva T, Dettori MT, Grimwood J, Cattonaro F, et al. The highquality draft genome of peach (Prunus persica) identifies unique patterns of genetic diversity, domestication and genome evolution. Nat Genet. 2013;45(5):487-94.

27. Zhu H, Xia R, Zhao BY, An YQ, Dardick DC, Callahan MA, Liu ZR. Unique expression, processing regulation, and regulatory network of peach (prunus persica) miRNAs. BMC Plant Biol. 2012;12(1):149.

28. Gao Z, Luo X, Shi T, Cai B, Zhang Z, Cheng ZM. Identification and validation of potential conserved microRNAs and their targets in peach (Prunus persica). Mol Cells. 2012;34:239-49.

29. Luo X, Gao Z, Shi T, Cheng Z, Zhang Z, Ni ZJ. Identification of miRNAs and their target genes in peach (Prunus persica L.) using high-throughput sequencing and degradome analysis. PLoS One. 2013;8(11):e79090.

30. Reig G, Alegre S, Gatius F, Iglesias I. Adaptability of peach cultivars [Prunus persica (L.) Batsch] to the climatic conditions of the Ebro Valley, with special focus on fruit quality. Sci Hortic-Amsterdam. 2015;190:149-60.

31. Byrne DH. Peach breeding trends: a worldwide perspective. Acta Hort. 2002;592:49-59.

32. Horvath DP, Anderson JV, Chao WS, Foley ME. Knowing when to grow: signals regulating bud dormancy. Trends Plant Sci. 2003;8(11):534-40.

33. Cirilli M, Bassi D, Ciacciulli A. Sugars in peach fruit: a breeding perspective. Hortic Res. 2016;2:15067.

34. Crisosto C, Costa G. The peach: botany, production, and uses. In: Layne DR, Bassi D, editors. . Cambridge: CAB International; 2008. p. 536-49.
35. Yu N, Li D, Tan Q, Zhang H, Gao D. Effect of UVB radiation on assimilate translocation and distribution in fruiting shoot of protected peach. Chin Appl Environment Biol. 2013;19(1):157-63.

36. Yu N, Tan Q, Tan Y, Zhang H, Gao D. Effects of UVB radiation on ${ }^{15} \mathrm{~N}$ urea absorption, utilization and distribution in fruiting shoot of peach under protected culture. Plant Nutrition Fertilizer Sci. 2012;18(2):491-8.

37. Luo X, Shi T, Sun H. Selection of suitable inner reference genes for normalization of microRNAs expression response to abiotic stresses by RT-qPCR in leaves, flowers and young stems of peach. Sci Hortic-Amsterdam. 2014;165(3):281-7.

38. Gao D. The current conditions and developing tendency of protected cultivation of fruit trees in China. Deciduous Fruits (in Chinese). 2016;48(1):1-4.

39. Li ZY, Gao DS, Qian S, Zhang JH, Li ZJ, Wang C. Effects of different light environments on the fruit quality of peach in greenhouse. J Anhui Agri Sci. 2009;37(21):9933V9934-63.

40. Brown BA, Jenkins GI. UV-B signaling pathways with different fluence-rate response profiles are distinguished in mature Arabidopsis leaf tissue by requirement for UVR8, HY5, and HYH. Plant Physiol. 2008;146:576-88.

41. Parul P, Samiksha S, Rachana S. Changing scenario in plant UV-B research: UV-B from a generic stressor to a specific regulator. J Photoch Photobio B. 2015;153:334-43.

42. Ulm R, Nagy F. Signalling and gene regulation in response to ultraviolet light. Curr Opin Plant Biol. 2005;8:477-82.

43. Hideg E, Jansen MA, Strid A. UV-B exposure, ROS, and stress: inseparable companions or loosely linked associates? Trends Plant Sci. 2013;18:107-15.

44. Chen XD. The effects of ultraviolet-B radiation intensity and different plasic film on development characteristics of peach flower and fruit in protected culture. Shandong Agriculture University, Horticulture and Engineering college: Master Thesis; 2009.

45. Hectors K, Prinsen E, De CW, Jansen MAK, Guisez Y. Arabidopsis thaliana plants acclimated to low dose rates of ultraviolet B radiation show specific changes in morphology and gene expression in the absence of stress symptoms. New Phytol. 2007:175:255-70.

46. Wang $B$, Sun $Y$, Song N. Identification of UVB-induced microRNAs in wheat. Genet Mol Res. 2013:12(4):4213-21.

47. Henderson IR, Zhang X, Lu C, Johnson L, Meyers BC, Green PJ. Dissecting Arabidopsis thaliana DICER function in small RNA processing, gene silencing and DNA methylation patterning. Nat Genet. 2006;38:721-5.

48. Chen L, Ren Y, Zhang Y, Xu J, Sun F, Zhang Z, Wang Y. Genome-wide identification and expression analysis of heat-responsive and novel microRNAs in Populus tomentosa. Gene. 2012;504:160-5.

49. Chen L, Zhang Y, Ren Y, Xu J, Zhang Z, Wang Y. Genome-wide identification of cold-responsive and new microRNAs in Populus tomentosa by highthroughput sequencing. Biochem Biophys Res Commun. 2012;417:892-6.

50. Li B, Duan H, Li J, Deng X, Yin W. Global identification of miRNAs and targets in Populus euphratica under salt stress. Plant Mol Biol. 2013;81:525-39.

51. Ren $Y$, Chen $L$, Zhang $Y$, Kang $X$, Zhang Z, Wang $Y$. Identification of novel and conserved Populus tomentosa microRNA as components of a response to water stress. Funct Integr Genomics. 2012;12:327-39.

52. Wang L, Mai YX, Zhang YC, Luo Q, Yang HQ. MicroRNA171c-targeted SCL6II, SCL6-III, and SCL6-IV genes regulate shoot branching in Arabidopsis. Mol Plant. 2010;3:794-806.

53. Curaba J, Talbot M, Li Z, Helliwell C. Over-expression of microRNA171 affects phase transitions and floral meristem determinancy in barley. BMC Plant Biol. 2013;13:6.

54. Fan T, Li X, Yang W, Xia K, Ouyang J, Zhang M. Rice osa-mir171c mediates phase change from vegetative to reproductive development and shoot apical meristem maintenance by repressin four OsHAM transcription factors. PLoS One. 2015;10(5):e0125833.

55. Huang W, Peng S, Xian Z, Lin D, Hu G, Yang L, Ren M, Li Z. Overexpression of a tomato mir171 target gene SIGRAS24 impacts multiple agronomical traits via regulating gibberellin and auxin homeostasis. Plant Biotechnol J. 2017;15(4):472-88.

56. Huang W, Xian Z, Kang X, Tang N, Li Z. Genome-wide identification, phylogeny and expression analysis of GRAS gene family in tomato. BMC Plant Biol. 2015:15:209.

57. Ma Z, Hu X, Cai W, Huang W, Xhou X, Luo Q, Yang H, Wang J, Huang J. Arabidopsis miR171-targeted scarecrow-like proteins bind to GT cis-elements and mediate gibberellin-regulated chlorophyll biosynthesis under light conditions. PLoS Genet. 2014;10(8):E1004519.

58. Barakat A, Sriram A, Park J, Zhebentyayeva T, Main D, Abbott A. Genome wide identification of chilling responsive microRNAs in Prunus persica. BMC Genomics. 2012;13:481. 
59. Müller-Xing R, Xing Q, Goodrich J. Footprints of the sun: memory of UV and light stress in plants. Front Plant Sci. 2014;5:474.

60. Kroger M, Meister K, Kava R. Low-calorie sweeteners and other sugar substitutes: a review of the safety issues. Compr Rev Food Sci F. 2006;5(2):35-47.

61. Guo X, Li S, Liu G, Fu Z, Li S. Seasonal changes in carbohydrate content and reated enzyme activity in fruit and leaves of "Yanfengyihao" peach variety. J Fruit Science (in Chinese). 2004;21(3):196-200.

62. Ding D, Li W, Han M, Wang Y, Fu Z, Wang B, Tang J. Identification and characterization of maize microRNAs involved in developing ears. Plant Biol. 2013;16(1):9-15.

63. Allen $\mathrm{E}$, Xie Z, Gustafson AM, Sung GH. Evolution of microRNA genes by inverted duplication of target gene sequences in Arabidopsis thaliana. Nat Genet. 2004;36(12):1282.

64. Robinson MD, McCarthy DJ, Smyth GK. EdgeR: a bioconductor package for differential expression analysis of digital gene expression data. Bioinformatics. 2010;26(1):139-40.

65. Luo X, Shi T, Sun H, Song J, Ni Z, Gao Z. Selection of suitable inner reference genes for normalisation of microRNA expression response to abiotic stresses by RT-qPCR in leaves, flowers and young stems of peach. Sci Hortic-Amsterdam. 2014;165(3):281-7.

66. Wang D, Gao Z, Du P, Xiao W, Tan Q, Chen X, Li L, Gao D. Expression of ABA metabolism-related genes suggests similarities and differences between seed dormancy and bud dormancy of peach (Prunus persica). Front Plant Sci. 2016;6:1248.

67. Karkacier M, Erbas M, Uslu MK, Aksu M. Comparison of different extraction and detection methods for sugars using amino-bonded phase HPLC. Chromatogr Sci. 2003;41(6):331-43.

68. Sornkanok V, Zheng H, Peng Q, Jiang Q, Wang H, Fang T, Liao L, Wang $\mathrm{L}, \mathrm{He} H, \mathrm{Han} Y$. Assessment of sugar components and genes involved in the regulation of sucrose accumulation in peach fruit. J Agric Food Chem. 2016;64:6723-9.

69. Shabala SN, Shabala SI, Martynenko AI, Babourina O, Newman IA. Salinity effect on bioelectric activity, growth, $\mathrm{Na}^{+}$accumulation and chlorophyll fluorescence of maize leaves: a comparative survey and prospects for screening. Aust J Plant Physiol. 1998;25:609-16.

\section{Submit your next manuscript to BioMed Central and we will help you at every step:}

- We accept pre-submission inquiries

- Our selector tool helps you to find the most relevant journal

- We provide round the clock customer support

- Convenient online submission

- Thorough peer review

- Inclusion in PubMed and all major indexing services

- Maximum visibility for your research

Submit your manuscript at www.biomedcentral.com/submit

) Biomed Central 